Article

\title{
Application of Ultraviolet Light-Emitting Diodes (UV-LED) to Full-Scale Drinking-Water Disinfection
}

\author{
Peter Jarvis ${ }^{1} \mathbb{1}$, Olivier Autin ${ }^{2}$, Emma H. Goslan ${ }^{1}$ and Francis Hassard $1, * \mathbb{C}$ \\ 1 Water Science Institute, Cranfield University, Cranfield MK43 0AL, UK; p.jarvis@cranfield.ac.uk (P.J.); \\ e.goslan@cranfield.ac.uk (E.H.G.) \\ 2 Typhon Treatment Systems Ltd., Unit 10, Penrith CA11 0BF, UK; oautin@typhontreatment.com \\ * Correspondence: francis.hassard@cranfield.ac.uk; Tel.: +44-12-3475-0111
}

Received: 31 July 2019; Accepted: 5 September 2019; Published: 11 September 2019

\begin{abstract}
Ultraviolet light-emitting diodes (UV-LEDs) have recently emerged as a viable technology for water disinfection. However, the performance of the technology in full-scale drinking-water treatment systems remains poorly characterised. Furthermore, current UV disinfection standards and protocols have been developed specifically for conventional mercury UV systems and so do not necessarily provide an accurate indication of UV-LED disinfection performance. Hence, this study aimed to test the hypothesis that a full-scale UV-LED reactor can match the Cryptosporidium inactivation efficiency of conventional mercury UV reactors. Male-specific bacteriophage (MS2) was used as the Cryptosporidium spp. surrogate microorganism. The time-based inactivation efficiency of the full-scale reactor was firstly compared to that of a bench-scale (batch-type) UV-LED reactor. This was then related to mercury UV reactors by comparing the fluence-based efficiency of the bench-scale reactor to the USEPA $90 \%$ prediction interval range of expected MS2 inactivation using mercury UV lamps. The results showed that the full-scale UV-LED reactor was at least as effective as conventional mercury UV reactors at the water-quality and drive-current conditions considered. Nevertheless, comparisons between the bench- and full-scale UV-LED reactors indicated that improvements in the hydraulic flow profile and power output of the full-scale reactor could help to further improve the efficiency of UV-LED reactors for municipal drinking water disinfection. This represents the world's first full-scale UV-LED reactor that can be applied at municipal water treatment works for disinfection of pathogenic microorganisms from drinking water.
\end{abstract}

Keywords: disinfection; Cryptosporidium; UV-LED; bacteriophage; chemical actinometry; drinking water

\section{Introduction}

Over the past decade, ultraviolet light-emitting diodes (UV-LEDs) have emerged as a viable technology for water disinfection [1,2]. UV-LEDs retain the advantages that conventional mercury UV lamps have over chemical disinfection methods, but also overcome a number of the disadvantages associated with UV lamps. Compared to their conventional counterparts, UV-LEDs are mercury-free, compact, robust, suffer minimal damage from repeated cycling, have longer life and reach full power faster. These advantages, along with virtually instantaneous start-ups and tunable wavelengths, offer great flexibility in UV-LED reactor design [3-5]. Despite these advantages, traditional applications of UV-LED reactors have focused on small-scale systems, which are not appropriate for municipal water treatment. UV-LEDs are small with typical dimensions between $1-4 \mathrm{~mm}^{2}$; therefore, LEDs can be positioned such that they emit radiation from different angles. These highly focused radiation patterns permit more options for orientation and hence, unique reactor design, compared to traditional UV lamps [6-8]. 
UV-LEDs have proven to be at least as effective as low-pressure UV (LPUV) lamps for water disinfection across a wide range of germicidal wavelengths (e.g., 250-285 nm) [8-11]. However, the wide-scale implementation of UV-LED water disinfection technology has been restricted by high capital costs, low output power and low wall-plug efficiency, despite these factors improving year on year [12]. As a result, technology uptake has largely been confined to small-scale, point-of-use, batch applications where the limitations of the technology are counteracted by longer exposure times to achieve the required UV dose $[5,6,13]$. Nevertheless, rapid improvements in UV-LEDs, along with the optimisation of the reactor design and system performance [8], have enabled the development of the world's first full scale UV-LED reactors that can be applied at municipal water treatment works (WTWs) (Typhon Treatment Systems Ltd.). Such reactors consist of a quartz glass tube with a series of UV-LEDs located around the perimeter of the cylinder, allowing UV light to penetrate into the water passing through the reactor. Thermal management is achieved using a water circulation system around the reactor vessel to dissipate the heat generated by the LEDs during operation. Accurate characterisation of disinfection performance of full-scale reactors is needed in order to ascertain the applicability of UV-LEDs for large-scale water disinfection.

Conventional UV reactors (using mercury lamps) are currently validated using biodosimetry. In this case, biodosimetry is the measurement of the sensitivity of a surrogate test microorganism to exposure to UV over a range of doses with calibrated inactivation kinetics. For UV reactors, the dose-response curve is usually obtained from collimated beam testing with the microorganism in the test water. The measured inactivation of the biodosimeter and the calibration curve are used to calculate a reduction equivalent dose (RED) $\left(\mathrm{mJ} / \mathrm{cm}^{2}\right)$. The challenge organism should be from the same stock of microorganisms and cultivated in an identical way. The process yields a UV dose-response curve for the reactor, which indicates the reduction equivalent dose for each log inactivation achieved at full-scale [14]. In addition, the method incorporates UV transmittance (UVT) into the UV dose calculation, thus standardizing the UV dose-response curves of the reactor to different indicative water quality, which is based solely on UVT. The first aim of this work was to, therefore, establish the performance of the UV-LED system using surrogate test microorganisms and benchmark this performance against conventional UV lamps. Cryptosporidium spp. was selected as our target organism of choice because UV is widely used and applied in instances where risk of Cryptosporidium occurrence is high. Cryptosporidium risk is linked to: (i) occurrence in source waters, (ii) their chlorine resistance (reported free chlorine contact times of 1000-10,000 $\mathrm{mg} \mathrm{min} / \mathrm{L}$ ) and (iii) propensity to pass through drinking water filters due to their small size $(4 \mu \mathrm{m}$ to $6 \mu \mathrm{m})$ [15]. UV treatment has an inactivation rate constant for Cryptosporidium parvum of $0.16 \mathrm{~cm}^{2} / \mathrm{mJ}$, which is significantly lower than the equivalent rate constant for free chlorine. Therefore, when UVT is accounted for, a log inactivation of 2 should require a UV dose of $12.5 \mathrm{~mJ} / \mathrm{cm}^{2}$ [16] suggesting UV is a suitable control strategy for this important human pathogen.

The second aim of the work was to establish whether a bench-scale UV-LED reactor could be used to mimic the disinfection performance of a full-scale continuous-flow UV-LED reactor for various water qualities. The benefits of such an approach being the potential for future validation at a much smaller scale, resulting in substantial time and cost savings. To ensure relevance and consistency, identical operating conditions were used and disinfection performance characterized using real water obtained from the same WTW.

Our hypothesis was that the full-scale reactor was able to reproduce the Cryptosporidium inactivation efficiency of conventional mercury UV reactors. Male-specific MS2 bacteriophage (MS2) was used as a conservative surrogate for Cryptosporidium, a practice used widely in UV disinfection studies [17,18]. The use of conservative indicators of $\log$ inactivation of Cryptosporidium has been subject to debate in the literature. For example, Wright and Lawryshyn, [19] suggested that the higher levels of log inactivation are difficult to test with conservative indicators. The use of indigenous organisms (e.g., aerobic spores) has been investigated, although application is usually limited to unfiltered water [20]. Other more sensitive surrogates for protozoan cysts in UV treatment have been suggested-for example, Bacillus 
subtilis spores, which have been applied to chlorine dioxide treatment [21] and UV disinfection studies undertaken for system validation (e.g., DVGW and ÖNORM). The USEPA has suggested that other challenge organisms such as bacteriophage T1, T7 and PhiX174 can be used in conjunction with MS2 to study the inactivation of virus, e.g., Enterovirus [22] and Cryptosporidium in parallel [18]. In this study, our selected sensitive indicator (PhiX174) was inactivated at such a rate that the dose could not be readily determined for the UV-LED reactor validation and hence, the decision was made to report only the MS2 data.

To test our hypothesis, we compared: (i) the time-based MS2 inactivation efficiencies of the fulland bench-scale UV-LED reactors at various UVTs $(90 \%$ and $97 \%)$ at $275 \mathrm{~nm}\left(\mathrm{UVT}_{275}\right)$ and drive currents; (ii) the fluence-based MS2 inactivation efficiency from the bench-scale reactor to mercury UV reactors by applying the USEPA UV dose-response prediction intervals for a mercury UV reactor, and; (iii) benchmark the full-scale UV-LED reactor against conventional mercury UV reactors based on its performance relative to the bench-scale reactor. To the authors' knowledge, this is the first example of a full-scale trial of a UV-LED reactor reported for microbiological disinfection of real waters for removal of indicator organisms representing clinically important human pathogens whose primary vector is treated drinking water.

\section{Materials and Methods}

\subsection{Apparatus for UV-LED, Low-Pressure UV (LPUV), and Fluence Measurement}

Both bench- and full-scale tests were conducted using post-rapid gravity filtered water obtained from a drinking WTW in the North of England. UVT $_{275}$ values were selected based on the minimum $(90 \%)$ and maximum $(97 \%)$ UVTs at the works from which the water samples were obtained. SuperHume was used to lower the UVT as per the USEPA guidelines. All validation standards recommend testing at various UVTs and SuperHume was used here as it has minimum interference with microorganisms used for validation testing. Bench-scale experiments were conducted at drive currents of 245, 350 and $525 \mathrm{~mA}$. Small differences in the drive current values and UVTs applied at full-scale compared to bench-scale were due to output increment limitations and variable source water respectfully. Therefore, similar drive currents of 100, 350 and $500 \mathrm{~mA}$ were selected which also reduced the energy consumption at full-scale.

Bench-scale UV-LED exposures were conducted using a 3.15 L capacity batch reactor (Typhon Treatment Systems Ltd., Penrith, UK) (Figure 1A). This reactor was commissioned with an identical diameter as the full-scale system but operated in batch mode (Figure 1B). UV-LED $100 \mathrm{~mW}$ lamps emitting at a maximum wavelength of $275 \mathrm{~nm}$ were constructed in an LED array (containing 40 LEDs) and positioned around the circumference of the reactor. Water was circulated around the reactor vessel to dissipate the heat generated by the LEDs during operation to ensure appropriate thermal management. The experimental setup was shielded from ambient light using a black cover. A magnetic stirrer (Stuart SB161, Cole-Parmer, St-Neots, UK) was placed underneath the quartz reactor vessel and a magnetic stir bar was placed inside the vessel and stirred to ensure mixing without vortex formation (Figure 1A). A single beam scanning UV/Vis Spectrophotometer (M501 $\pm 0.002 \mathrm{Abs}$, Camspec, Leeds, UK) was used for all absorbance measurements and the samples were vortexed (ZX3 Advanced Vortex Mixer, VELP Scientifica, Usmate Velate, Italy) for at least five seconds prior to analysis. All measurements were performed in triplicate. 
A.

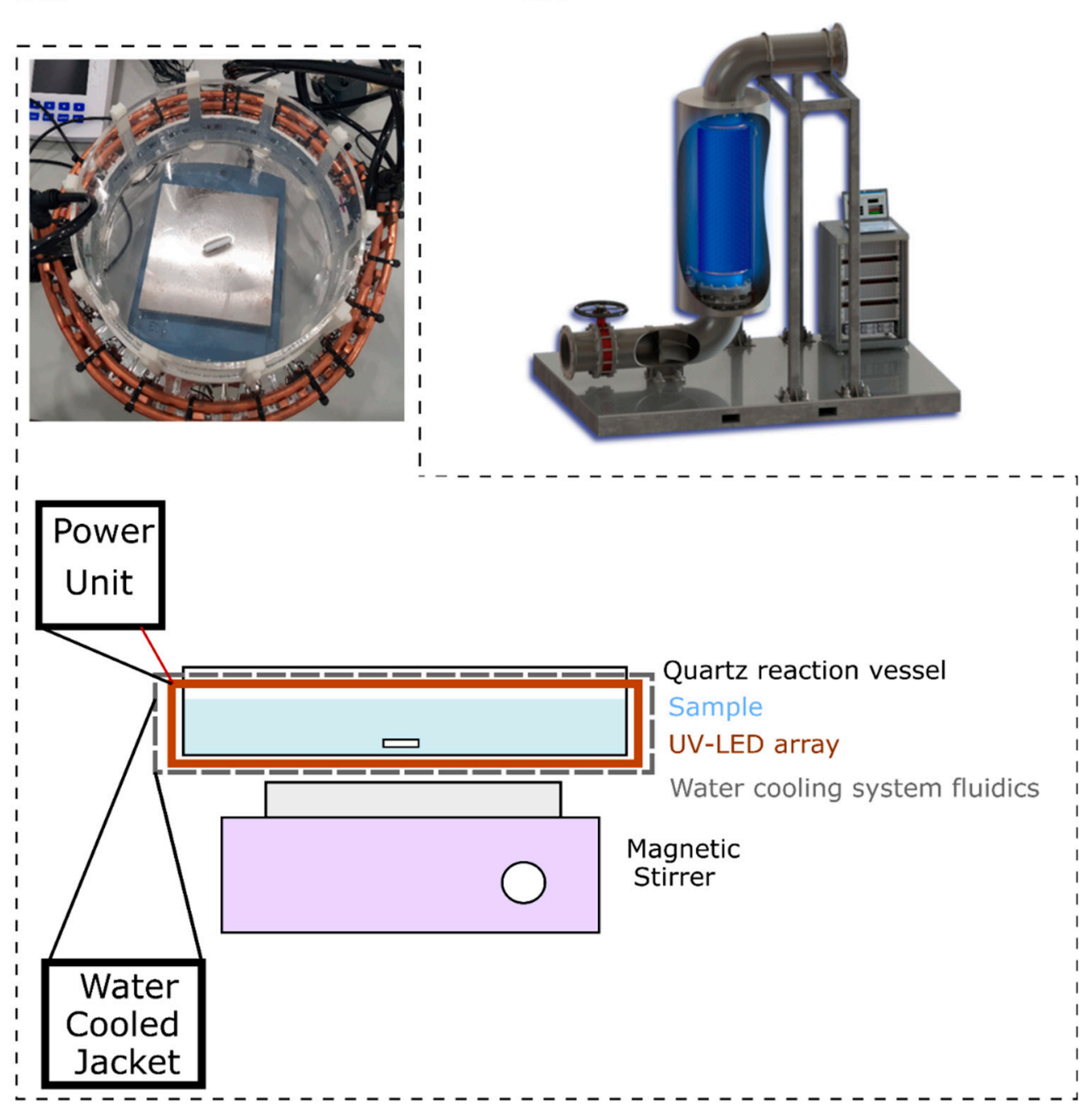

B.

1
1
1
1
1
1
1
1
1
1
1
1
1
1
1
1
1
1
1
1
1
1
1
1
1
1
1
1

Figure 1. (A) Experimental setup of bench-scale ultraviolet light-emitting diode (UV-LED) reactor; (B) UV-LED reactor at a full-scale water treatment works (WTW) in the North of England, UK.

A full-scale UV-LED reactor was operated at a municipal WTW in the North of England. The WTW treated 28 mega-litres per day (MLD) and was comprised of conventional treatment of lowland, river-derived surface water: $\mathrm{pH}$ adjustment was achieved using sulphuric acid, coagulation with aluminum sulphate and polyelectrolyte followed by settlement through lamella clarification, rapid gravity filtration and chlorine disinfection using free chlorine. The filtration step directly preceding the full-scale UV reactors comprised six rapid gravity filters (RGF) ( $800 \mathrm{~mm}$ sand with $400 \mathrm{~mm}$ anthracite) with a combined filter outlet turbidity target of 0.1 NTU. During the full-scale trial, the combined filter outlet turbidity was 0.09 NTU. A UV-LED unit was positioned downstream of each RGF filter. Each UV-LED unit treated circa $20 \%$ of the WTW flow and $100 \%$ of the flow from each respective RGF. This reactor was commissioned with an identical diameter as the bench-scale system but operated in plug flow (Figure 1B). It was considered that inactivation kinetics would be proportionate and comparable between the bench- and full-scale reactor. Each full-scale reactor was able to treat flows of up to 6 MLD at a wavelength and power output of $275 \mathrm{~nm}$ and $100 \mathrm{~mW}$, respectively. The LEDs in the full-scale system were identical to the bench-scale testing above. A total of 1000 UV-LEDs were arranged in an array which was consistent between bench-scale and full-scale (Figure 1B).

A uridine chemical actinometer was used to determine the I, which is the UV fluence or UV light intensity $\left(\mathrm{mW} / \mathrm{cm}^{2}\right)$ at each drive current. A quantity of $10 \mathrm{~mL}$ of a $0.923 \mathrm{~g} / \mathrm{L}$ uridine (Thermo Fisher, UK) and deionised (DI) water stock solution was added to $3.15 \mathrm{~L}$ of DI water to obtain a $0.012 \mathrm{mM}$ 
uridine solution. The maximum absorbance of the solution at $262 \mathrm{~nm}\left(\mathrm{~A}_{262}, \mathrm{~cm}^{-1}\right)$ was measured prior to UV exposure. Samples were taken after 20,40,60 and 120 s and the $A_{262}$ was measured for each sample.

The UV intensity, $I\left(\mathrm{~mW} / \mathrm{cm}^{2}\right)$ at each drive current was then calculated as follows in Equation (1)

$$
I=\left(\frac{\ln \left(\frac{A_{262}^{0}}{A_{262}}\right)}{t}\right) \times\left(\frac{U}{2.303 \times 1000 \times \epsilon_{262} \times \phi}\right)
$$

where, $A_{262}^{0}=$ actinometer solution absorbance at $262 \mathrm{~nm}$ before being irradiated; $A_{262}=$ actinometer solution absorbance at $262 \mathrm{~nm}$ after irradiation; $\frac{\ln \left(\frac{A_{262}^{0}}{A_{262}}\right)}{t}\left(\mathrm{~s}^{-1}\right)$, is the gradient of the linear trendline of the curve of $\ln \left(\frac{A_{262}^{0}}{A_{262}}\right)$ against time, $\mathrm{t}(\mathrm{s}) ; U=7.23 \times 10^{19}$ is the photon energy emitted at $275 \mathrm{~nm}$, which when multiplied by Avogadro's number, gives the energy per mol of photon (J/E); $\epsilon_{262}=8000$ $\left(\mathrm{M}^{-1} \mathrm{~cm}^{-1}\right)$ is the molar extinction coefficient of uridine at $262 \mathrm{~nm}$ [23] and $\phi=0.016$ is the quantum yield (number of events/number of photons absorbed) of uridine photohydration (mol/E) [24] and $2.303=\ln (10)$. It is assumed that the quantum yield remains constant throughout the UV exposures. The temperature of the water was monitored throughout the actinometry experiments and short exposure times prevented temperature increase due to UV exposure from the UV-LEDs.

Once the UV intensity was known, the UV fluence (D) $\left(\mathrm{mJ} / \mathrm{cm}^{2}\right)$ irradiated over each exposure time was calculated using Equation (2), taking into account changes in the effective dose caused by impurities which reduce the effective dose to the organism:

$$
D=I \times \frac{1-10^{-A 275 \times d}}{A_{275} \times d \times \ln (10)} \times t
$$

$I=$ Average UV intensity $\left(\mathrm{mW} / \mathrm{cm}^{2}\right)$ determined using chemical actinometry which accounts for reactor geometry and $d=$ radius of the reactor dish $(\mathrm{cm})$. Equation (2) was adapted from USEPA (2006).

\subsection{Microorganism Propagation and MS2 Assay}

Freeze-dried culture vials of MS2 (ATCC 15,597-B1) and its Escherichia coli host (ATCC 15,597) were obtained from LGC Standards Ltd. (Teddington, UK). Each set of microorganisms were rehydrated and propagated in accordance with their respective ATCC product sheets. A modified double-agar layer technique was used for the MS2 assay after UV-LED exposures. A tube-free technique was selected due to the observed assay recovery and the clarity of plaques formed [25]. Prior to exposure, E. coli was inoculated into $20 \mathrm{~mL}$ of Tryptone Soy Broth (TSB) (Oxoid Ltd., Basingstoke, UK). The bacterial suspension was cultivated overnight (12 to $16 \mathrm{~h}$ ) in an incubator shaker (ES-80, Grant-bio, Shepreth, UK) at $37^{\circ} \mathrm{C}$ and $180 \mathrm{rpm}$ to an optical density of at least 1 . After exposures, $100 \mu \mathrm{L}$ of the overnight culture was pipetted onto $55 \mathrm{~mm}$ diameter Petri dishes containing a solidified $8 \mathrm{~mL}$, $1 \%$ bottom agar layer (medium 271, ATCC, Manassas, VA, USA) before $30 \mu \mathrm{L}$ was pipetted onto the bacterial suspension droplet. Two milliliters of molten $0.3 \%$ top agar at 50 to $52{ }^{\circ} \mathrm{C}$ was added before the Petri dish was covered and swirled vigorously to ensure a homogeneous top layer. The agar was left to solidify for $20 \mathrm{~min}$ before plates were inverted and placed into an incubator (Heraeus Incubator, Thermo Scientific, Bishop's Stortford, UK) at $37^{\circ} \mathrm{C}$ for 16 to $24 \mathrm{~h}$. A colony counter (Stuart SC6, Cole-Parmer, St-Neots, UK) was used to count the number of plaque-forming units (PFU) remaining on each plate. Two controls were plated before and after each assay (four in total). One control contained E. coli but no bacteriophage and an abiotic control (absence of microorganisms) were added in the other. The same approach was undertaken for analysis of samples obtained from the bench experiments and the full-scale study. 


\subsection{UV Disinfection}

Water samples were obtained post RGF from the WTW and were autoclaved $\left(121^{\circ} \mathrm{C}, 15 \mathrm{~min}\right)$ and stored at $4{ }^{\circ} \mathrm{C}$ prior to all UV exposures for the batch experiments. For each exposure, $100 \mu \mathrm{L}$ of MS2 was spiked into a $3.15 \mathrm{~L}$ water sample to obtain a final concentration of $10^{4}-10^{5} \mathrm{PFU} / \mathrm{mL}$. Super-Hume (UAS of America Inc., Lake Panasoffkee, FL, USA), a fulvic/humic acid concentrate, was used to adjust the water $\mathrm{UVT}_{275}$ to the required transmittance. After an initial sample was taken prior to UV irradiation, five more samples were taken following intervals of $1 \mathrm{~s}$ of exposure. The collimated beam apparatus had a pneumatically controlled shutter window operated with a timer accurate to $\pm 0.1 \mathrm{~s}$. The collimated beam apparatus had a magnetic stirrer and was undertaken according to USEPA guidelines. The bench-scale UV-LED system had an in-built timer controlling the on/off of the LEDS which was user-defined and controlled electronically. Samples were immediately diluted using autoclaved and $0.22 \mu \mathrm{m}$ filtered 1X phosphate buffered saline pH 7.4 (Sigma Aldrich, Haverhill, UK), stored at $4{ }^{\circ} \mathrm{C}$ and plated using the aforementioned techniques within $2 \mathrm{~h}$. At full-scale, a similar starting concentration range of $10^{4}-10^{5} \mathrm{PFU} / \mathrm{mL}$ for MS2 was used. The MS2 bacteriophage was dosed into the feed chamber directly preceding the UV-LED reactor through a peristaltic pump. A stable and dispersed concentration of MS2 was ensured through repeated testing of inlet water concentration of MS2. The testing commenced once a stable population was achieved. MS2 negative controls ensured that background E. coli bacteriophage were accounted for due to potential susceptibility of the E. coli host to environmental bacteriophage from full-scale sampling.

\subsection{Inactivation Kinetics}

Linear regression was used to obtain the time-based $\left(k_{t}, \mathrm{~s}^{-1}\right)$ and fluence-based $\left(k_{F}, \mathrm{~cm}^{2} / \mathrm{mJ}\right)$ inactivation constants by linearly fitting the $\log$ inactivation, $\log \left(\mathrm{I}_{\mathrm{MS} 2}\right)$, to the UV exposure time Equation (3) and fluence Equation (4), respectively [7] Time-based inactivation was the most appropriate calculation for the full-scale UV-LED reactor as the dose was difficult to determine directly.

$$
\begin{aligned}
& \log \left(\mathrm{I}_{\mathrm{MS} 2}\right)=\log \left(\frac{N_{0}}{N_{t}}\right)=k_{t} \times t \\
& \log \left(\mathrm{I}_{\mathrm{MS} 2}\right)=\log \left(\frac{N_{0}}{N_{t}}\right)=k_{F} \times D
\end{aligned}
$$

where $\log \left(\mathrm{I}_{\mathrm{MS} 2}\right)$ is the $\log$ inactivation of MS2 virus, the $N_{0}(\mathrm{PFU} / \mathrm{mL})$ is the initial concentration and $N_{t}(\mathrm{PFU} / \mathrm{mL})$ is the MS2 concentration after a specific UV exposure time. $k_{F}$ is the fluence-based inactivation constant and $k t$ is the time-based inactivation constant.

\subsection{Statistical Analysis}

The bench-scale experiments were conducted based on a randomised, full-factorial design developed using JMP ${ }^{\circledR}$ statistical software (SAS, Cary, NC, USA). All experiments were duplicated independently with three method replicates for each sample. Excel 2018 (Microsoft, Redmond, WA, USA) was used for linear regression and to calculate standard deviations. Further statistical analyses were completed using SPSS ${ }^{\circledR}$ Statistics 25 (IBM, Portsmouth, UK). The significance of the effect of drive current on the inactivation efficiency was determined using the Welch's one-way analysis of variance (ANOVA) $(p<0.05)$ and post-hoc test using the Games-Howell method. Assumptions of the ANOVA considering Welch's adjustments were met.

\section{Results and Discussion}

In order to benchmark the performance of the full-scale UV-LED reactor against conventional mercury UV reactors, the fluence-based inactivation efficiency of the bench-scale reactor was considered. This performance was then benchmarked against mercury UV reactors through comparison of the fluence-based performance of the bench-scale UV-LED reactor to a range of expected performance for 
different UV doses for mercury UV collimated beam reactors [14]. Separately, the time-based inactivation efficiency of the full-scale and bench-scale reactors were then directly compared. Time-based inactivation efficiency was used as UV fluence is difficult to determine at full-scale. It was considered that there was no difference other than wavelength between the UV light emitted from an LED and from a mercury UV tube, i.e., the inactivation efficacy of the photons from LEDs are similar to the photons from conventional systems.

\subsection{UV Fluence Determination and MS2 Inactivation}

The chemical actinometry regression analysis showed a strong linear relationship (Goodness of fit: $R^{2} \geq 0.99$ in all experiments) between uridine degradation and UV exposure (Figure 2). UV intensities of $4.87,5.67$ and $8.57 \mathrm{~mW} / \mathrm{cm}^{2}$ were then calculated at drive currents of 245,350 and $525 \mathrm{~mA}$, respectively (Figure 2; Table 1). The UV fluence delivered by the bench-scale UV-LED was then determined to be between 0 and $42.8 \mathrm{~mJ} / \mathrm{cm}^{2}$, depending on the exposure time and drive current from the uridine actinometry experiments (Table 1). This showed that the quantum yield remained constant throughout the UV exposures. The method also displayed good reproducibility with minimal standard deviation (typically less than $10 \%$ of the mean) after two replicates $(n=2)$.

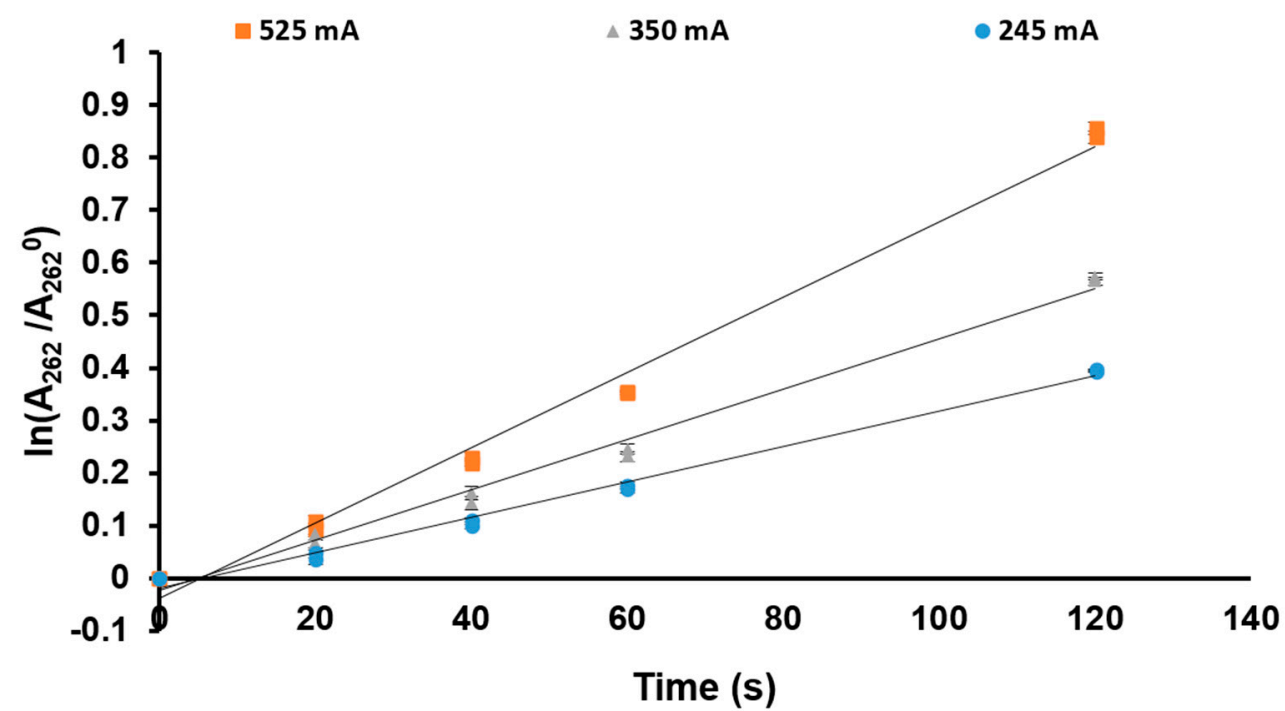

Figure 2. Linear regression for uridine UV exposures at different drive currents. The trend line was not fitted to the intercept.

Table 1. UV fluence delivered by bench-scale UV-LED reactor at each drive current (derived using uridine chemical actinometer).

\begin{tabular}{|c|c|c|c|c|c|c|c|}
\hline \multirow{3}{*}{$\begin{array}{l}\text { Drive Current } \\
\qquad(\mathrm{mA})\end{array}$} & \multirow{3}{*}{$\begin{array}{c}I \\
\left(\mathrm{~mW} / \mathrm{cm}^{2}\right)\end{array}$} & \multicolumn{6}{|c|}{ Time (s) } \\
\hline & & 0 & 1 & 2 & 3 & 4 & 5 \\
\hline & & \multicolumn{6}{|c|}{ UV Fluence $\left(\mathrm{mJ} / \mathrm{cm}^{2}\right)$} \\
\hline 245 & 4.87 & 0 & 4.87 & 9.75 & 14.62 & 19.50 & 24.37 \\
\hline 350 & 5.76 & 0 & 5.76 & 11.52 & 17.28 & 23.04 & 28.80 \\
\hline 525 & 8.57 & 0 & 8.57 & 17.13 & 25.70 & 34.27 & 42.83 \\
\hline
\end{tabular}

The UV-LED reactor achieved high levels of MS2 inactivation (log removals 0.5-3.9) depending on drive current. These values are similar to those reported using conventional mercury LPUV lamps that have shown that maximum log inactivation of MS2 occurs at doses of 5-139 mJ/cm ${ }^{2}$ [14-16] and that the efficacy of UV systems decreases at lower UVTs and due to association of viruses with particles. For example, Watercare [26] showed that water at a $\mathrm{UVT}_{254}(39 \%-46 \%)$ required very high doses $\left(20-50 \mathrm{~mJ} / \mathrm{cm}^{2}\right)$ to attain a 2-log inactivation of MS2 in a wastewater disinfection process. However, 
UV-LEDs have different characteristics to LPUV and numerous studies have compared inactivation efficiencies between UV-LEDs and LPUV. For example, Bowker et al. [3] found that LPUV lamps were more effective than UV-LEDs at $255 \mathrm{~nm}$ and $275 \mathrm{~nm}$ for 2-log disinfection of MS2 at $41 \mathrm{~mJ} / \mathrm{cm}^{2} \mathrm{UV}$ fluence. On the other hand, Beck et al. [8] found that that $260 \mathrm{~nm}$ UV-LEDs were more efficient than LPUV lamps requiring $30 \mathrm{~mJ} / \mathrm{cm}^{2}$ compared to $35 \mathrm{~mJ} / \mathrm{cm}^{2}$ for a 2-log MS2 inactivation. The study also found greater disinfection efficiencies than Bowker et al. [3] using LEDs at both $260 \mathrm{~nm}$ and $280 \mathrm{~nm}$. Kim et al. [11] obtained higher inactivation of MS2 with LEDs compared to LPUV lamps at both wavelengths of 266 and $279 \mathrm{~nm}$, respectively. In addition to the slightly different wavelengths investigated in these studies, the great diversity in UV-LED reactor configurations, radiation profiles and microbiological methods makes direct comparisons difficult [27]. Beck et al. [8] noted that the discrepancies between their study and that of Bowker et al. [3] were most likely due to the fact that the latter considered UV-LEDs to be a monochromatic light source. Instead, there seems to be a consensus in recent studies that UV-LEDs are polychromatic light sources with Gaussian-distributed emission spectra with relatively narrow bandwidths $[27,28]$. It is thought that polychromatic light could have multiple pathways of inactivation by: (i) supplying photons which target the absorption maxima of different microorganisms; (ii) provide alternative mechanisms of inactivation (e.g., free radical or reactive oxygen species production); (iii) crosslinking more of the DNA/RNA at key active sites within the genetic code and (iv) damaging other functional structures within microorganisms (e.g., capsid) [29]. Alternatively, direct absorption of UV light for MS2 at wavelengths of $275 \mathrm{~nm}$ could provide the means for the effective disinfection shown here. This can be substantiated through comparison of the spectral sensitivity of Cryptosporidium. Which is greatest at between 254 and $280 \mathrm{~nm}$, peaking at $\sim 275 \mathrm{~nm}$ [30]. A further benefit of operating at UV-LEDs at $275 \mathrm{~nm}$ is that this wavelength provides a good balance between disinfection efficacy and UV-LED energy consumption, since there is an approximate doubling in the energy demand moving from $275 \mathrm{~nm}$ to $260 \mathrm{~nm}[5,10]$. The ability of UV-LEDs to be tuned to a desired wavelength in addition to their diversity in structure and radiation profiles mean that UV-LEDs should not be considered as only a substitute source of light but a tool for precision in water treatment $[2,13,27]$.

In this work, the relative UV fluence values obtained were substantiated by the rate at which the concentration of MS2 changed in the reactor during the UV disinfection experiments at each drive current (Figure 3A,B). At a drive current of $245 \mathrm{~mA}$ and $97 \% \mathrm{UVT}_{275}$, the fluence inactivation rate $\left(k_{F}\right)$ was $0.171 \mathrm{~cm}^{2} / \mathrm{mJ}\left(R^{2}=0.985\right)$. In contrast, slower rates of inactivation of $0.156 \mathrm{~cm}^{2} / \mathrm{mJ}\left(R^{2}=0.975\right)$ and $0.134 \mathrm{~cm}^{2} / \mathrm{mJ}\left(R^{2}=0.951\right)$ were observed at drive currents of 350 and $525 \mathrm{~mA}$, respectively (Figure 4). The $\mathrm{UVT}_{275}$ had a significant effect on the inactivation kinetics for MS2 ( $\left.\mathrm{t}_{\text {Welch }} p<0.05\right)$. To illustrate, there was a decrease in the rate of MS2 inactivation from 0.171 to $0.109 \mathrm{~cm}^{2} / \mathrm{mJ}$ as the $\mathrm{UVT}_{275}$ decreased from $97 \%$ to $90 \%$ at a drive current of $245 \mathrm{~mA}$ (Figures 3 and 4). At drive currents of 525, 350 and $245 \mathrm{~mA}$, the rates of MS2 inactivation decreased by $6 \%, 14 \%$ and $37 \%$, respectively, as $\mathrm{UVT}_{275}$ declined from $97 \%$ to $90 \%$, suggesting increased drive current reduced the impact of impurities on the inactivation efficiency of UV-LEDs. 


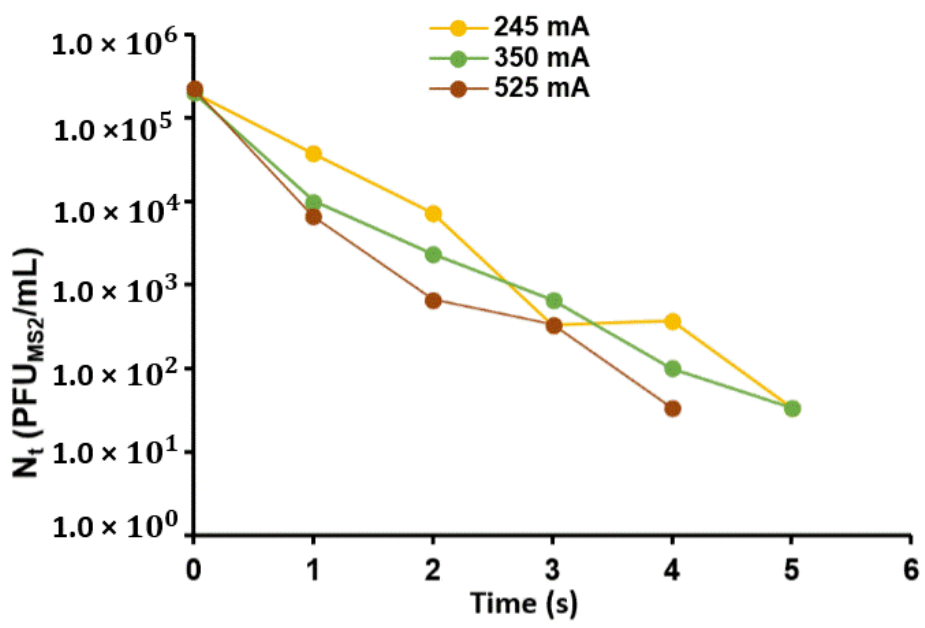

(A)

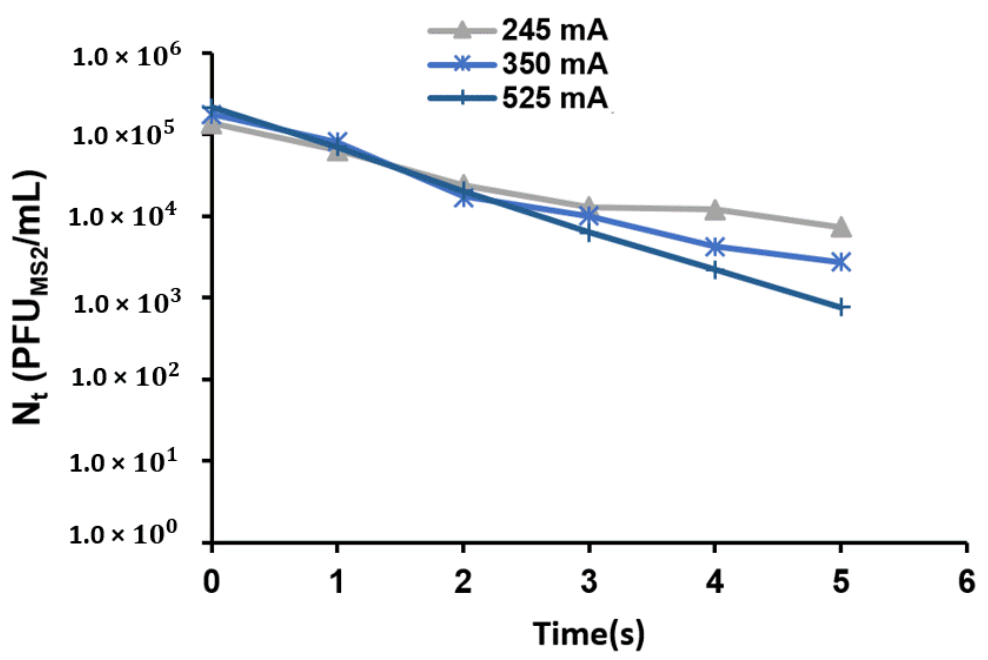

(B)

Figure 3. Change in MS2 concentration over time (A) $\mathrm{UVT}_{275}=97 \%$; (B) $\mathrm{UVT}_{275}=90 \%$ in the bench-scale experiments.

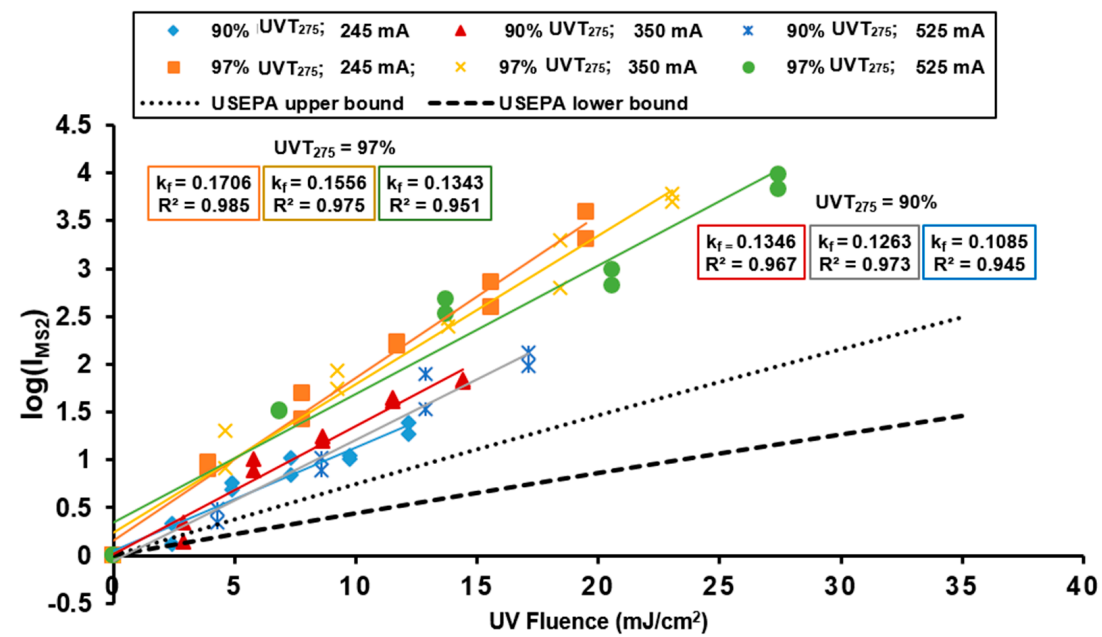

Figure 4. Comparison of UV dose-response curves for the bench-scale UV-LED reactor and mercury UV reactors. The calculated $k$ values did not consider the presence of a shoulder and the intercept was not fitted to 0 . The UV fluence was corrected for $\mathrm{UVT}_{275}$. 


\subsection{UV-LED Bench- and Full-Scale Comparison}

The results from the bench-scale reactor were then compared to those seen for the full-scale system using time-based inactivation efficiencies. At $>350 \mathrm{~mA}$ ( $70 \%$ drive current), similar inactivation efficiencies of 0.359 and $0.36 \mathrm{~s}^{-1}$ were observed for the bench- and full-scale reactors at $90 \% \mathrm{UVT}_{275}$, respectively. At $97 \% \mathrm{UVT}_{275}$, the reactors showed similar log inactivation at higher drive currents. However, as the drive current was reduced, a deviation in the disinfection performance of the reactors occurred. As a result, there was a $22 \%$ decrease in the $k t$ from $0.713 \mathrm{~s}^{-1}$ in the bench-scale reactor to $0.562 \mathrm{~s}^{-1}$ in the full-scale reactor at equivalent drive current $(350 \mathrm{~mA})$. The two reactors showed similar trends for the $k t$ across the drive currents at a $\mathrm{UVT}_{275}$ of $90 \%$ (Figure 4). At lower $\mathrm{UVT}_{275}$ of $90 \%$ the two reactors had very similar performance as the drive current changed (Figure 4), with $k t$ ranging from $0.201-0.509 \mathrm{~s}^{-1}$ as the drive current increased from 245 to $525 \mathrm{~mA}$. The reasons for the differences in the performance of the full-scale system to the bench-scale reactor at the higher UVT may have been: fine-scale fluence differences in the reactors due to the distribution of the hydraulic residence time, orientation of UV-LEDS, adsorption, reflection and refraction of the UV light through water, and the LED and lamp intensity profile [16]. It is well established that the calculated fluence data obtained on scale-up with continuous-flow systems rarely mirrors the biodosimetry obtained using collimated beam experiments for conventional UV lamp systems [31]. For example, lower inactivation rate constants have been found for $E$. coli in continuous flow compared to collimated beam systems. For example, Sommer [32] reported an inactivation efficiency of $0.187 \mathrm{~mJ} / \mathrm{cm}^{2}\left(R^{2}=0.98\right)$ for E. coli, whereas Watercare [26] found inferior performance of continuous-flow systems with $0.066 \mathrm{~mJ} / \mathrm{cm}^{-2}$ for coliforms in wastewater systems. Havelaar [33] showed similar performance is achievable in LPUV systems operated continuously, with inactivation efficiencies of $0.168\left(R^{2}=0.53\right)$ for $E$. coli. In addition, the reduction equivalent dose of one pilot scale system was $60 \%$ lower than the calculated fluence for Clostridia spores compared to equivalent collimated beam systems [16,31,34]. Initial microbial resistance has been suggested as one reason for an offset in performance between completely mixed flow-through reactors and collimated beam systems [35]. While the reactors tested here used UV-LEDs, similarities between the bench- and full-scale tests included the use of the same: test organism, LEDs and drive current applied (UV fluence). Differences were principally associated with the hydraulics in the reactors. Computational fluid dynamics (CFD) modelling is improving the fluence calculation within continuous-flow systems to account for hydraulic effects and differences in effective fluence at each spatial location within a continuous-flow system. For example, a study by Jenny et al. [36], demonstrated that UV-LED spatial arrangement is critical for optimal continuous-flow UV-LED design. CFD was found to aid the design and was able to simulate experimental results obtained through biodosimetry. Here, it was shown that the performance at full-scale was similar to that seen at bench-scale at $90 \% \mathrm{UVT}_{275}$. The greatest differences between bench- and full-scale occurred at $97 \%$ $\mathrm{UVT}_{275}$. The probable reason for this being that this effect was limited to differences in hydrodynamics between bench- and full-scale, the impact of which was masked by impurities present at lower $\mathrm{UVT}_{275}$ of $90 \%$ but became evident as impurity levels reduced at $97 \% \mathrm{UVT}_{275}$.

\subsection{Comparison of Bench-Scale UV-LED and Mercury UV Reactors}

At a $\mathrm{UVT}_{275}$ of $90 \%$, the dose-response curves of the bench-scale UV-LED reactor were $52 \%-65 \%$ higher than the USEPA 90\% percent predication interval upper band for mercury UV reactors (Figure 4). An increase of $\mathrm{UVT}_{275}$ to $97 \%$ resulted in the $k_{F}$ values increasing substantially to $0.171,0.156$ and $0.134 \mathrm{~cm}^{2} / \mathrm{mJ}$, for 245,350 and $525 \mathrm{~mA}$, respectively. Hence, the UV fluence-response curves at both $\mathrm{UVT}_{275}$ tested were well-above the USEPA prediction interval and demonstrated that dose was proportional to inactivation in the $\mathrm{UVT}_{275}$ and UV fluence tested (Figure 4).

Overall, the findings of this study indicate that the full-scale UV-LED performance for the time-based inactivation of MS2 was similar to the bench-scale reactor at a $\mathrm{UVT}_{275}$ of $90 \%$. Since the fluence-based performance of the bench-scale UV-LED reactor falls above the USEPA prediction interval for mercury UV reactors, it can be seen that the full-scale reactor was at least as effective 
as mercury UV reactors at this $\mathrm{UVT}_{275}$. At $97 \% \mathrm{UVT}_{275}$, the bench-scale UV-LED outperformed the full-scale reactor. An enhanced inactivation efficiency was observed for the full-scale reactor for $90 \%$ to $97 \% \mathrm{UVT}_{275}$, as evidenced by a $k t$ which was $0.202-0.499 \mathrm{~s}^{-1}$ at $90 \% \mathrm{UVT}_{275}$ and $0.367-0.816 \mathrm{~s}^{-1}$ at $97 \% \mathrm{UVT}_{275}$ (Figure 5). However, this difference was not statistically significant at higher drive current ( $\left.t_{\text {Welch }} p>0.05\right)$, suggesting performance reductions can be mitigated through an increased drive current. As the inactivation rate of the full-scale UV-LED system at $97 \% \mathrm{UVT}_{275}$ was higher than both bench-scale and full-scale UV-LED reactors at $90 \% \mathrm{UVT}_{275}$. We theorise that the performance of the full-scale UV-LED would still be better than conventional lamps at $97 \% \mathrm{UVT}_{275}$. Energy savings will occur through use of UV-LEDs during subsequent improvements in wall-plug efficiency and UV LED life, a view aligned with previous research [12]. At present, the maximum wall-plug efficiency (WPE) of UV-LEDs is approximately 10\% for laboratory-scale devices. The UV-LEDs used in this study, at both full- and bench-scale, had a WPE of $4 \%$, with the remaining input power converted to heat. In comparison, the WPE for LPUV is 30\%-35\% and for high-pressure UV lamps is $10 \%-20 \%$ [12]. The overall efficiency of a UV system is a function of WPE $x$ reactor efficiency $x$ germicidal efficiency. The reactor efficiency and the germicidal efficiency of LED systems has been shown to be higher than that seen for mercury lamps; therefore, the overall efficiency is currently comparable. The rapid improvement in the WPE of UV LEDs should enable substantial energy savings in the future. In addition, other strategies to reduce energy demand may be through the application of pulsed irradiation. High-frequency pulses rather than continuous UV-LED irradiation may facilitate significant energy savings for UV-LEDS, resulting in high power output in conjunction with better thermal management due to the intermediate "off" cycles [1]. Such an approach warrants further investigation to understand the impact of this approach on LED wear and lifespan [37].

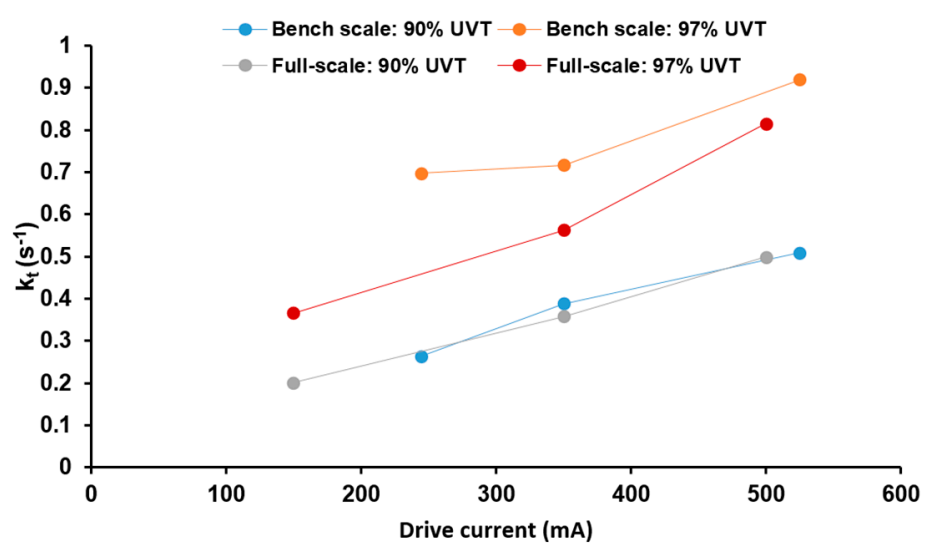

Figure 5. Time-based efficiency against drive current for UV-LED bench- and full-scale reactor.

As noted previously, the wide-scale implementation of UV-LED water disinfection technology has been restricted by capital costs despite incremental improvements in UV-LED design [12]. A recent cost comparison of technologies for disinfection suggested conventional UV treatments cost $0.04-0.06$ cents (USD) per $\mathrm{m}^{3}$ of water treated with a plant capacity of $100-50,000 \mathrm{~m}^{3}$ per day [38], which was cheaper than most other emerging technologies. This confirmed earlier findings from Cotton et al. [39] who showed that the cost of UV systems decreases as WTW size increases. However, this cost estimation was developed based on systems using LPUV lamps with a higher dose $\left(40 \mathrm{~mJ} / \mathrm{cm}^{2}\right)$ for 2-log Cryptosporidium. Previous cost estimates of development parameters for UV-LEDs, such as commercial power output per LED $(\mathrm{mW})$ and price per LED, overestimated the development of commercial LEDs by several years. For example, the LEDs used here had a power output of $100 \mathrm{~mW}$ compared to the anticipated power output of $675 \mathrm{~mW}$ expected at this time in Ibrahim et al. [12]. Future studies need to refine these cost estimates considering the slower development of UV-LED technology. However, future savings are expected to be achieved in the running costs due to the extended UV LED life compared to LPUVs and the expected increase in electrical efficiency, especially for those 
WTWs required to meet disinfection targets for Cryptosporidium. Here, it has been demonstrated that from a performance perspective, UV-LEDs are suitable for Cryptosporidium inactivation at two UVTs and three drive currents. UV-LEDs were tested for MS2 inactivation (Figure 6), additional testing on different indicator organisms, pathogens and source waters is needed [40]. The performance of UV-LEDs had near equivalence between bench- and full-scale reactors. Future improvements to dose delivery efficiency will enable UV-LEDs to reach their full potential for drinking water disinfection.

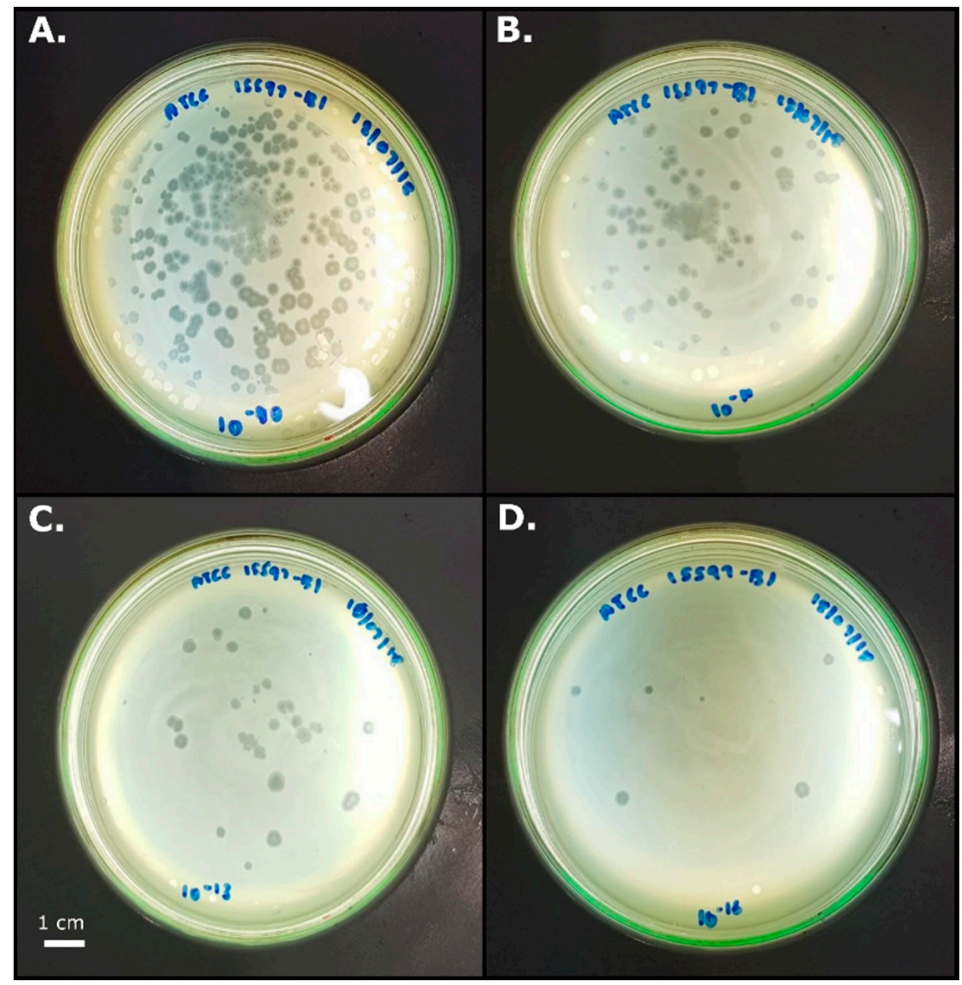

Figure 6. E. coli confluent lawn from double-layer agar plates. Plates inoculated with autoclaved and UV-irradiated water which was subsequently spiked with $10^{12}$ plaque-forming units (PFU) of MS2. Plates represent different dilutions of MS2 stock solution $(\mathbf{A}) 10^{10} ;$ (B) $10^{11} ;$ (C) $10^{13}$; (D) $10^{16}$ showing the upper (A) and lower limits (D) of detection of the method e.g., >1000; and 3 PFU/plate.

\section{Conclusions}

This study has shown that the full-scale UV-LED reactor was at least as effective compared to mercury UV reactors for inactivation of Cryptosporidium surrogates at $\mathrm{UVT}_{275}$ values above $90 \%$. Comparisons between the bench- and full-scale UV-LED reactors indicated that although the full-scale reactor performance was similar to that of the bench-scale reactor at $90 \% \mathrm{UVT}_{275}$, some differences were seen at higher UVTs. These differences were explained by hydraulic effects and differences in effective fluence at each point within a continuous-flow system. This study reports the world's first full-scale UV-LED reactor for municipal drinking water treatment. A UV dose of $4.5-27 \mathrm{~mJ} / \mathrm{cm}^{2}$ was suitable to achieve 0.5-3.9 log inactivation of Cryptosporidium surrogate MS2 using UV-LEDs, which was dependent on UVT and drive current. At $97 \% \mathrm{UVT}_{275}$ and $350 \mathrm{~mA}$ drive current, the UV-LED obtained a 2-log MS2 inactivation at a UV dose of $9.2 \mathrm{~mJ} / \mathrm{cm}^{2}$. The adoption of widely applicable methods, such as chemical actinometry, for UV fluence determination is recommended. Further study into the applicability of uridine for UV fluence determination at full-scale is, therefore, also recommended. This will allow for a more accurate representation and comparison of reactor performance. It is hoped that the methods applied in this study will contribute to the development of standard experimental procedures and validation protocols for UV-LED water disinfection. Lastly, a more holistic approach to the design and implementation of UV disinfection systems will enable the 
development of technologies that are "fit-for-purpose". This will then encourage the identification of larger-scale UV-LED applications which make use of the unique benefits the technology offers. Identifying specific disinfection applications for UV-LEDs will also serve as a catalyst for further innovation and development. These findings are of interest to water treatment practitioners as they provide demonstrable scale-up of UV-LED and operation at a real WTW. This work presents a novel template for use of UV-LEDs for disinfection and more broadly on the role of UV light on inactivation of clinically important human pathogens.

Author Contributions: Data curation, P.J. and F.H.; Formal analysis, F.H., Funding acquisition, O.A. and F.H.; Methodology, O.A., P.J. and F.H.; Supervision, O.A. and F.H.; Writing-original draft, P.J. and F.H.; Writing-review and editing, P.J., E.H.G. and F.H.

Funding: None to declare.

Acknowledgments: The authors would like to thank the WTW operators for assisting with the full-scale trials.

Conflicts of Interest: The authors declare no conflict of interest. The funders had no role in the design of the study; in the collection, analyses, or interpretation of data; in the writing of the manuscript, or in the decision to publish the results.

\section{Abbreviations}

$\begin{array}{ll}\text { ANOVA } & \text { Analysis of Variance } \\ \text { CFD } & \text { Computational fluid dynamics } \\ \text { DI } & \text { Deionised water } \\ \text { KI/KIO } 3 & \text { Potassium iodide/potassium iodate } \\ \text { LPUV } & \text { Low-pressure ultraviolet } \\ \text { MLD } & \text { Mega-litre per day } \\ \text { MS2 } & \text { Bacteriophage MS2 } \\ \text { NTU } & \text { Nephelometric turbidity unit } \\ \text { PFU } & \text { Plaque-forming units } \\ \text { RED } & \text { Reduction equivalent dose } \\ \text { RGF } & \text { Rapid Gravity Filter } \\ \text { TSB } & \text { Tryptone soy broth } \\ \text { USEPA } & \text { United States Environmental Protection Agency } \\ \text { UV } & \text { Ultraviolet } \\ \text { UV-LED } & \text { Ultraviolet light-emitting diodes } \\ \text { UVT } & \text { Ultraviolet transmittance } \\ \text { WTW } & \text { Water Treatment Works }\end{array}$

\section{References}

1. Song, K.; Taghipour, F.; Mohseni, M. Microorganisms inactivation by continuous and pulsed irradiation of ultraviolet light-emitting diodes (UV-LEDs). Chem. Eng. J. 2018, 343, 362-370. [CrossRef]

2. Kheyrandish, A.; Taghipour, F.; Mohseni, M. UV-LED radiation modeling and its applications in UV dose determination for water treatment. J. Photochem. Photobiol. A Chem. 2018, 352, 113-121. [CrossRef]

3. Bowker, C.; Sain, A.; Shatalov, M.; Ducoste, J. Microbial UV fluence-response assessment using a novel UV-LED collimated beam system. Water Res. 2011, 45, 2011-2019. [CrossRef] [PubMed]

4. Song, K.; Mohseni, M.; Taghipour, F. Application of ultraviolet light-emitting diodes (UV-LEDs) for water disinfection: A review. Water Res. 2016, 94, 341-349. [CrossRef] [PubMed]

5. Oguma, K.; Kanazawa, K.; Kasuga, I.; Takizawa, S. Effects of UV irradiation by light emitting diodes on heterotrophic bacteria in tap water. Photochem. Photobiol. 2018, 94, 570-576. [CrossRef] [PubMed]

6. Lui, G.Y.; Roser, D.; Corkish, R.; Ashbolt, N.J.; Stuetz, R. Point-of-use water disinfection using ultraviolet and visible light-emitting diodes. Sci. Total Environ. 2016, 553, 626-635. [CrossRef] [PubMed]

7. Oguma, K.; Kita, R.; Sakai, H.; Murakami, M.; Takizawa, S. Application of UV light emitting diodes to batch and flow-through water disinfection systems. Desalination 2013, 328, 24-30. [CrossRef] 
8. $\quad$ Beck, S.E.; Ryu, H.; Boczek, L.A.; Cashdollar, J.L.; Jeanis, K.M.; Rosenblum, J.S.; Lawal, O.R.; Linden, K.G. Evaluating UV-C LED disinfection performance and investigating potential dual-wavelength synergy. Water Res. 2017, 109, 207-216. [CrossRef] [PubMed]

9. Sholtes, K.A.; Lowe, K.; Walters, G.W.; Sobsey, M.D.; Linden, K.G.; Casanova, L.M. Comparison of ultraviolet light-emitting diodes and low-pressure mercury-arc lamps for disinfection of water. Environ. Technol. 2016, 37, 2183-2188. [CrossRef] [PubMed]

10. Rattanakul, S.; Oguma, K. Inactivation kinetics and efficiencies of UV-LEDs against Pseudomonas aeruginosa, Legionella pneumophila, and surrogate microorganisms. Water Res. 2018, 130, 31-37. [CrossRef] [PubMed]

11. Kim, D.-K.; Kim, S.-J.; Kang, D.-H. Inactivation modeling of human enteric virus surrogates, MS2, Q $\beta$, and ФX174, in water using UVC-LEDs, a novel disinfecting system. Food Res. Int. 2017, 91, 115-123. [CrossRef] [PubMed]

12. Ibrahim, M.A.S.; Macadam, J.; Autin, O.; Jefferson, B. Evaluating the impact of LED bulb development on the economic viability of ultraviolet technology for disinfection. Environ. Technol. 2014, 35, 400-406. [CrossRef] [PubMed]

13. Chen, J.; Loeb, S.; Kim, J.-H. LED revolution: Fundamentals and prospects for UV disinfection applications. Environ. Sci. Water Res. Technol. 2017, 3, 188-202. [CrossRef]

14. USEPA. Ultraviolet Disinfection Guidance Manual for the Final Long Term 2 Enhanced Surface Water Treatment Rule; USEPA: Washington, DC, USA, 2006.

15. Muhammad, N.; Sinha, R.; Krishnan, E.R.; Piao, H.; Patterson, C.L.; Cotruvo, J.; Cumberland, S.L.; Nero, V.P.; Delandra, C. Evaluating surrogates for Cryptosporidium removal in point-of-use systems. J. Am. Water Work. Assoc. 2008, 100, 98-107. [CrossRef]

16. Hijnen, W.; Beerendonk, E.; Medema, G. Inactivation credit of UV radiation for viruses, bacteria and protozoan (oo)cysts in water: A review. Water Res. 2006, 40, 3-22. [CrossRef] [PubMed]

17. Beck, S.E.; Rodriguez, R.A.; Hawkins, M.A.; Hargy, T.M.; Larason, T.C.; Linden, K.G. Comparison of UV-Induced Inactivation and RNA Damage in MS2 Phage across the Germicidal UV Spectrum. Appl. Environ. Microbiol. 2016, 82, 1468-1474. [CrossRef] [PubMed]

18. Mackey, E.D.; Hargy, T.M.; Wright, H.B.; Malley James, P., Jr.; Cushing, R.S. Implications for UV reactor validation. J. Am. Water Work. Assoc. 2002, 94, 62. [CrossRef]

19. Wright, H.B.; Lawryshyn, Y.A. An assessment of the bioassay concept for UV reactor validation. Proc. Water Environ. Fed. 2000, 378-400. [CrossRef]

20. Mamane-Gravetz, H.; Linden, K.G. UV disinfection of indigenous aerobic spores: Implications for UV reactor validation in unfiltered waters. Water Res. 2004, 38, 2898-2906. [CrossRef]

21. Chauret, C.P.; Radziminski, C.Z.; Lepuil, M.; Creason, R.; Andrews, R.C. Chlorine Dioxide Inactivation of Cryptosporidium parvum Oocysts and Bacterial Spore Indicators. Appl. Environ. Microbiol. 2001, 67, $2993-3001$. [CrossRef]

22. Rodriguez, R.A.; Bounty, S.; Beck, S.; Chan, C.; McGuire, C.; Linden, K.G. Photoreactivation of bacteriophages after UV disinfection: Role of genome structure and impacts of UV source. Water Res. 2014, 55, 143-149. [CrossRef] [PubMed]

23. Cataldo, F. Uridine as Photochemical Actinometer: Application to UV-LED Reactors. Eur. Chem. Bull. 2017, 6, 405-409. [CrossRef]

24. Kuhn, H.; Braslavsky, S.; Schmidt, E. Chemical actinometry (IUPAC technical report). Pure Appl. Chem. 2004, 76, 2105-2146. [CrossRef]

25. Kauffman, K.M.; Polz, M.F. Streamlining standard bacteriophage methods for higher throughput. MethodsX 2018, 5, 159-172. [CrossRef] [PubMed]

26. Watercare. Pilot Plant Investigations, Surrogate Study, Results and Recommendations; Disinfection review group report; Water Care Services Ltd.: Auckland, New Zealand, 2002.

27. Kheyrandish, A.; Mohseni, M.; Taghipour, F. Development of a method for the characterization and operation of UV-LED for water treatment. Water Res. 2017, 122, 570-579. [CrossRef]

28. Beck, S.E.; Hull, N.M.; Poepping, C.; Linden, K.G. Wavelength-Dependent Damage to Adenoviral Proteins Across the Germicidal UV Spectrum. Environ. Sci. Technol. 2018, 52, 223-229. [CrossRef] [PubMed]

29. Song, K.; Mohseni, M.; Taghipour, F. Mechanisms investigation on bacterial inactivation through combinations of UV wavelengths. Water Res. 2019, 163, 114875. [CrossRef] 
30. Linden, K.G.; Shin, G.; Sobsey, M.D. Comparative effectiveness of UV wavelengths for the inactivation of Cryptosporidium paroum oocysts in water. Water Sci. Technol. 2001, 43, 171-174. [CrossRef]

31. Hijnen, W.A.; Van Der Veer, A.J.; Beerendonk, E.F.; Medema, G.J. Increased resistance of environmental anaerobic spores to inactivation by UV. Water Sci. Technol. Water Supply 2004, 4, 55-61. [CrossRef]

32. Sommer, R.; Haider, T.; Cabaj, A.; Pribil, W.; Lhotsky, M. Time fluence reciprocity in UV disinfection of water. Water Sci. Technol. 1998, 38, 145-150. [CrossRef]

33. Havelaar, A.H.; Pot-Hogeboom, W.M.; Kooti, W.; Pot, R. F-Specific bacteriophages as indicators of the disinfection efficiency of secondary effluent with Ultraviolet Radiation. J. Int. Ozone Assoc. 1987, 9, 353-367. [CrossRef]

34. Schoenen, D.; Zemke, V.; Kolch, A. Effect of the reflection of UV rays in the disinfection of drinking water. Zent. Hyg. Umweltmed. 1991, 191, 396-405.

35. Severin, B.; Suidan, M.; Rittmann, B.; Engelbrecht, R. Inactivation kinetics in a flow-through UV reactor. J. Water Pollut. Control Fed. 1984, 56, 164-169.

36. Jenny, R.M.; Jasper, M.N.; Simmons, O.D.; Shatalov, M.; Ducoste, J.J. Heuristic optimization of a continuous flow point-of-use UV-LED disinfection reactor using computational fluid dynamics. Water Res. 2015, 83, 310-318. [CrossRef] [PubMed]

37. Li, X.; Cai, M.; Wang, L.; Niu, F.; Yang, D.; Zhang, G. Evaluation survey of microbial disinfection methods in UV-LED water treatment systems. Sci. Total Environ. 2019, 659, 1415-1427. [CrossRef] [PubMed]

38. Dore, M.H.I.; Singh, R.G.; Khaleghi-moghadam, A.; Achari, G. Cost differentials and scale for newer water treatment technologies. Int. J. Water Resour. Environ. Eng. 2013, 5, 100-109.

39. Cotton, C.A.; Owen, D.M.; Cline, G.C.; Brodeur, T.P. UV disinfection costs for inactivating Cryptosporidium. J. Am. Water Work. Assoc. 2001, 93, 82-94. [CrossRef]

40. Farrell, C.; Hassard, F.; Jefferson, B.; Leziart, T.; Nocker, A.; Jarvis, P. Turbidity composition and the relationship with microbial attachment and UV inactivation efficiency. Sci. Total Environ. 2018, 624, 638-647. [CrossRef]

(C) 2019 by the authors. Licensee MDPI, Basel, Switzerland. This article is an open access article distributed under the terms and conditions of the Creative Commons Attribution (CC BY) license (http://creativecommons.org/licenses/by/4.0/). 